\title{
Transparência digital nos parlamentos dos países de língua portuguesa
}

\author{
Digital transparency on parliaments of Portuguese-speaking countries
}

\author{
Antonio Teixeira de Barros \\ Docente e pesquisador do Programa de Mestrado em \\ Ciência Política do Centro de Formação da Câmara dos \\ Deputados, Esplanada dos Ministérios, Brasília, DF, \\ Brasil \\ antonibarros@gmail.com
}

Resumo: Analisa os instrumentos digitais de transparência política dos parlamentos dos oito países de língua portuguesa. Os websites das casas legislativas foram examinados com o propósito de mapear as ferramentas oferecidas nas seguintes áreas: dados administrativos, informações legislativas, prestação de contas sobre gastos, meios de divulgação institucional, formas de contato e relacionamento com a sociedade. Os resultados indicam maior investimento na divulgação de informações sobre o funcionamento, a agenda de trabalho e a oferta de noticiário eletrônico sobre a atuação das instituições parlamentares. Os principais déficites de transparência são registrados no item acerca da prestação de contas sobre os gastos dos parlamentos. Outra lacuna identificada se refere à falta de canais de interatividade e participação cidadã.

Palavras-chave: Sociologia da transparência política; Transparência parlamentar; Parlamentos dos países de língua portuguesa; Websites legislativos.

Abstract: This paper analyzes digital instruments of political transparency of parliaments of the eight Portuguese-speaking countries. The websites of the chambers were examined with the purpose of mapping tools offered in the following areas: administrative data, legislative information, accountability for spending, institutional means of disclosure forms of contact and relationship with society. The results indicate greater investment in dissemination of information about the operation, the agenda and the provision of electronic news on the performance of parliamentary institutions. The main deficits of transparency are recorded in item about accountability for the expenditure of parliaments. Another identified gap refers to the lack of interactivity and citizen participation channels.

Keywords: Sociology of political transparency; Parliamentary transparency; Parliaments of the Portuguese-speaking countries; Legislative websites. 


\section{Introdução}

Este artigo tem como objeto de análise os websites dos parlamentos da Comunidade dos Países de Língua Portuguesa (CPLP), como o propósito de mapear as ferramentas digitais usadas para proporcionar transparência às atividades dessas instituições. Foram monitorados os websites dos parlamentos nacionais dos oito países que formam a CPLP ${ }^{1}$ durante o segundo semestre do ano de 2014.

O estudo inscreve-se na concepção de transparência política como fenômeno socialmente construído, ou seja, resultante das relações entre os diferentes atores políticos, representados por dois polos: o Estado e a sociedade. A ideia de transparência política como produção social encontra respaldo no pressuposto sociológico de que as necessidades e os valores sociais são definidos e redefinidos de acordo com a dinâmica social, marcada pela vontade e o julgamento que comandam as motivações para o agir na esfera pública, consoante com as diferenciações relativas às especificidades das épocas históricas, a configuração das sociedades situadas, com suas classes e grupos sociais. Afinal, as necessidades sociais não são homogêneas e nem fixas e nem seguem a leis pré-estabelecidas. Ao contrário, elas são diversificadas, em decorrência da pluralidade de sujeitos que as expressam e são também criadas e recriadas em função dos progressos no campo político e cultural (FIGUEIREDO, 1989).

Exemplo disso é que nem sempre a transparência política foi defendida ou considerada uma necessidade social e moralmente relevante. Houve épocas em que se defendia exatamente o contrário, ou seja, o segredo e o resguardo das informações políticas, da atuação do Estado e de suas instituições. Isso reforça mais um postulado sociológico de que a vontade que comanda $\mathrm{o}$ agir social varia segundo as diferenciações inerentes a cada contexto histórico, a cada sociedade. Afinal, as estruturas sociais condicionam e interferem no arbítrio dos sujeitos sociais e políticos, uma vez que são os sujeitos segundo as condições sócio-históricas que criam situações concretas no mundo social e são os fatores daí resultantes que podem ser revelados (FIGUEIREDO, 1989).

Foram consideradas as seguintes áreas temáticas para o estudo: dados administrativos sobre as casas legislativas, informações sobre as atividades legislativas, prestação de contas e balanços financeiros, meios de divulgação institucional das atividades dos parlamentos, formas de contato e relacionamento com a sociedade, e a divulgação sobre as atividades de educação política.

\footnotetext{
A CPLP foi criada em 1996, com o objetivo de aprofundar a amizade mútua e a cooperação entre os seus membros. Reúne os oitos países lusófonos: Angola, Brasil, Cabo Verde, Moçambique, Guiné Bissau, São Tomé e Príncipe e Timor Leste.
}

Antes da apresentação dos dados, o texto apresenta uma breve reflexão transparência política aplicada ao contexto dos países da CPLP.

\section{Parlamentos da CPLP e os desafios da transparência digital}

Apesar de ainda guardar resquícios da cultura do segredo (votação secreta, fórum privilegiado), as instituições parlamentares avançaram nos últimos anos na adesão aos projetos políticos de transparência e accountability que começaram a ter impactos relevantes no cenário internacional ${ }^{2}$. Esses projetos passaram a fazer parte do debate político internacional e também se tornaram relevantes no âmbito da teoria política e dos estudos sociológicos sobre as redefinições dos regimes democráticos, denominadas por Giddens (2009) de "democratização da democracia". Trata-se de um processo inerente à modernização reflexiva, que passou a imprimir um ritmo de "[...] revolução permanente das formas de organização política, de suas estruturas, funções e também das relações e práticas sociais." (BECK; GIDDENS; LASH, 1994, p. 12).

As deficiências da democracia liberal, com seu modelo de representação e participação focado na competição eleitoral sugerem formas mais radicais de democratização e modos intitucionais de revisão das próprias engrenagens do regime. Para Giddens, a transparência, associada às concepções de accountability, responsivity e adovacy apresentam potencial para aumentar a densidade da democracia, unindo o Estado à mobilização reflexiva da sociedade. Isso, contudo, requer inteligência diretiva na gestão política e burocrática, além de permeabilidade política das instituições, confiança ativa e autonomia dos indivíduos e grupos.

A publicidade em relação às ações de governo já foi devidamente defendida por autores renomados, inclusive Norberto Bobbio (2005, p. 28), segundo o qual “[...] o poder político é o poder público [...] mesmo quando não é público, não age em público, esconde-se do público, não é controlado pelo público." Para Bobbio, a República diferencia-se dos regimes autoritários ou absolutistas exatamente porque há um controle público do poder e a livre formação de uma opinião pública. O caráter público do governo representativo - ou nos termos contemporâneos da discussão política, a transparência das decisões governamentais - é ressaltado na passagem em que o autor argumenta que nos casos em que a assembleia é a reunião dos representantes do povo, quando então a decisão seria pública apenas para estes e não para todo o povo, as

\footnotetext{
2 Para um panorama sobre o contexto internacional, consultar (FRICK, 2004).
} 
reuniões da assembleia devem ser abertas ao público de modo que qualquer cidadão a elas possa ter acesso (BOBBIO, 2005, p. 30).

A conexão entre política e internet é cada vez mais visível devido ao crescente uso dessa ferramenta pelos atores políticos e pelos cidadãos na vida cotidiana. As instituições políticas buscam cada vez mais visibilidade e legitimidade perante a opinião pública. Afinal, a visibilidade é da natureza da política (THOMPSON, 1995). Na esfera política parlamentar, marcada pelo debate, formulação e aprovação de políticas públicas, os efeitos das internet são crescentes. Cumprindo um papel mediador entre sociedade e Estado, conforme Weber (1999), o parlamento assume ainda as funções de fiscalização do Executivo e de representação dos interesses da população, que atenderiam, entre outras coisas, à lógica de conexão eleitoral dos parlamentares, ou seja, a reeleição. E para que tal conexão tenha maior potencial de sucesso, há que se garantir a visibilidade do mandato e do próprio parlamento, além de credibilidade e confiança do eleitorado nos representantes e na própria instituição parlamentar.

Pesquisadores de vários países percebem o incremento nas estratégias de transparência por parte das instituições legislativas nos últimos anos. Para autores como Leston-Bandeira (2012), o uso de dispositivos digitais é uma tentativa de reação ao descrédito e à apatia política das atuais sociedades, preocupantes não só pela sua importância para as eleições, do ponto de vista parlamentar, mas ainda mais para a democracia. Assim, os parlamentos percebem a internet como uma ferramenta de modernização da visibilidade institucional, capaz de promover um estilo político mais dialógico. As mudanças trazidas pela internet afetam principalmente o relacionamento das instituições políticas com a sociedade. A tendência é que os parlamentos utilizem a internet como forma de suprir lacunas de transparência e accountability e de, com isso, buscar legitimidade perante a opinião pública.

Nesse contexto, a internet constitui atualmente um importante mecanismo de conexão das instituições parlamentares com a sociedade e propicia relevantes instrumentos efetivos para os projetos de parlamentos abertos (FARIA, 2012). Aliás, a transparência é considerada um dos requisitos inerentes às instituições parlamentares, além da probidade, da representatividade, acessibilidade, responsabilidade e eficácia política (SÁEZ; MERCEDEZ, 2013).

A internet, tornou-se, portanto, uma ferramenta útil para a atuação dos órgãos parlamentares. Afinal, no contexto de uma sociedade de multirredes (BAUMAN, 2000), as instituições políticas deparam-se com a lógica da inevitabilidade digital, resultante do processo de encolhimento do mundo (HARVEY, 1992) e de constituição de novos modos do fazer político. A internet renovou o campo político, com um novo tipo de copresença, por meio da atuação online dos atores. Ressalta-se nesse aspecto, a capacidade de agência do usuário de internet, com sua múltipla atuação (espectador, ator e operador). Os parlamentos tiveram que aderir, portanto, à política de signos para criar e representar modos de pertencimento do cidadão (RIBEIRO, 2000).

No regime de visibilidade da democracia de público (MANIN, 1995, 2013), a política informacional (CASTELLS, 2003) torna-se cada vez mais imperativa. Afinal, a geração, o processamento e a transmissão de informações e imagens tornaram-se as fontes fundamentais de produtividade de poder. Por isso, os parlamentos tendem cada vez mais a recorrer a estratégias de sedução política pela internet, cujos websites são o foco da divulgação, uma espécie de "palanque virtual" ou de outdoor na esfera virtual (CASTELLS, 2003). É oportuno ressaltar que a literatura especializada mostra como a relação entre política internet tornou-se inevitável, com o uso quase generalizado de websites pelas instituições políticas (FRICK, 2004; TRECHSEL et al., 2004).

$\mathrm{Na}$ esfera parlamentar, marcada pelo debate, formulação e aprovação de políticas públicas, os efeitos das internet são crescentes, como registra a literatura especializada no internacional e no contexto brasileiro (NORRIS, 2003; TRECHSEL et al., 2004; FARIA, 2012). Nesse contexto, pesquisadores de vários países percebem o incremento nas estratégias de transparência digital por parte das instituições políticas. Tais estratégias se justificam, em linhas gerais, pela busca de maior visibilidade e legitimidade social.

Nesses termos, estudo de Silva et al. (2009) aponta três dimensões em que efetivamente os sites parlamentares podem contribuir para o avanço da democracia e da representação política: publicidade, accountability e participação. "Falar em publicidade, accountability e participação significa pensar em três elementos fundamentais para a dinâmica das democracias hoje." (SILVA et al., 2009, p. 4). Se a publicidade é inerente ao poder, tornar públicos os atos dos representantes políticos é indispensável para a democracia e o exercício da representação política. Assim, uma função dos sites das instituições parlamentares seria disponibilizar o máximo de informações aos cidadãos. Cabe às instituições legislativas e parlamentares, portanto, desenvolverem estratégias para a construção de interfaces digitais dessas instituições com os cidadãos, por meio de seus portais na internet.

A accountability pode se entendida como a responsabilidade dos representantes e das instituições parlamentares de prestarem contas com regularidade à 
sociedade e aos cidadãos, por se tratar de uma relação assimétrica de poder. A participação, por sua vez, é entendida como retroalimentação da representação, em um processo de negociação contínua ou representação circular (URBINATI, 2006). Trata-se de um modo de incluir os eleitores na produção das decisões políticas. No caso dos parlamentos, isso implica abertura para a influência do cidadão sobre os agentes da representação. Isso significa considerar novos fluxos de inputs políticos e novos mecanismos de interação e de governança digital, com a incorporação das tecnologias avançadas à atividade parlamentar (FRICK, 2004).

O debate sobre democracia digital, transparência política dos parlamentos, accountability e temas afins está diretamente relacionado com a questão da confiança do cidadão nas instituições políticas. Cabe ressaltar que o tema da confiança dos cidadãos nas instituições sociais e políticas e da legitimidade dos regimes políticos é um dos assuntos mais debatidos nas Ciências Sociais, já há algum tempo (GIDDENS, 1991). A confiança institucional é um dos elementos centrais da modernidade, na forma de credibilidade pública, o que se reflete diretamente na imagem e na reputação de governos e instituições públicas. Trata-se de “[...] uma forma de fé na qual a segurança adquirida em resultados prováveis expressa mais um compromisso com algo do que apenas uma compreensão cognitiva." (GIDDENS, 1990, p. 29). Dessa forma, a confiança expressa no nível de adesão ao regime democrático e na utilização das instituições oficiais constitui um fator simbólico relevante para a estabilidade política e institucional. No cenário atual, a confiança e a legitimidade das instituições políticas, especialmente as parlamentares, é constantemente posta à prova Miguel (2008).

A discussão está conectada à ideia de que a confiança da população nas instituições de seus países ou comunidades é um aspecto essencial para a legitimidade do regime político e, portanto, para a estabilidade do sistema social. De maneira geral, podemos dizer que quanto mais confiança nas instituições, maiores as chances de desenvolvimento de um regime democrático satisfatório para a população (NORRIS, 1999; LIJPHART, 2001; TILLY, 2008). No sistema representativo, com parlamentos, isso se adquire ainda mais importância.

Por outro lado, já se tornou comum o diagnóstico de vários autores (MOISÉS, 2009) sobre a crise de descrédito por que passam as instituições políticas contemporâneas. Pesquisas recentes revelam que o nível de confiança da população nas instituições políticas nunca foi tão baixo, especialmente em relação às Casas Legislativas (LESTON-BANDEIRA, 2012). Existe uma gama de razões que atuam em conjunto para construir esse contexto de desconfiança política, como o histórico de recorrentes escândalos políticos, informações distorcidas e instâncias políticas disfuncionais. O desenvolvimento de uma cidadania cada vez mais crítica e vigilante é apontado como um dos fatores do aumento da desconfiança (RIBEIRO, 2011).

As jovens democracias, como a maioria dos países de língua portuguesa, padecem da "síndrome de desconfiança generalizada" (RIBEIRO, 2011). Mas seriam as causas da desconfiança política nesses países as mesmas identificadas nas democracias avançadas? Segundo Ribeiro (2011), as razões são distintas e as explicações devem ser buscadas no contexto cultural e histórico. Enquanto nas democracias consolidadas a desconfiança é fruto do elevado nível de escolarização e informação dos cidadãos críticos, nas jovens democracias, a explicação estaria na desilusão dos cidadãos com o funcionamento concreto das instituições políticas, principalmente os parlamentos.

Os oito países que integram a Comunidade dos Países de Língua Portuguesa (CPLP) atualmente apresentam grande diversidade e assimetrias em termos de organização política e de institucionalização do regime democrático. Esses países compartilham traços culturais e linguísticos comuns, mas também são muito distintos em termos políticos. Não é objetivo deste artigo esmiuçar os pormenores relacionados às diferenças e semelhanças, mas apenas situar brevemente a atuação dos parlamentos de cada um desses países, a fim de compreender qual o papel da internet na relação entre tais parlamentos e a sociedade. Um traço comum relevante é que a maioria deles é formada por jovens democracias, após regimes autoritários que ainda hoje repercutem na vida política dessas nações.

Do ponto de vista específico dos parlamentos, cabe destacar que a maioria apresenta organização unicameral. Apenas o Brasil é bicameral. Ademais, os parlamentos dos países da CPLP enfrentam o desafio relativo ao aperfeiçoamento da democracia, além de tentar equilibrar as forças políticas relacionadas com a distribuição de poderes de agenda entre os diferentes atores no interior do Legislativo, resultando em ganhos democráticos no que se refere à estabilidade, accountability e representatividade (ANASTASIA; MELO; SANTOS, 2004).

Já existem vários estudos que avaliam a transparência e a abertura dos parlamentos ${ }^{3}$. Não pretendemos replicálos, mas aprofundar alguns aspectos, considerando sobretudo eventuais alterações inerentes ao próprio dinamismo da internet e o seu uso para fins de promover a transparência política das instituições parlamentares no âmbito específico da CPLP.

\footnotetext{
${ }^{3}$ Eis alguns desses estudos: Frick (2004), Sáez e Mercedez (2013) e Silva et al. (2009).
} 


\section{Análise dos dados}

Todas as informações compiladas para o estudo foram captadas diretamente nos websites das instituições legislativas, conforme consta no Quadro 1. Dos oitos países da CPLP, o Brasil é o único com o parlamento bicameral, composto pela Câmara dos Deputados e o Senado Federal. Para efeitos de comparação, optamos pela Câmara dos Deputados, pela sua analogia em relação às demais instituições legislativas analisadas.

Antes da análise das informações disponíveis no websites dos parlamentos dos países da CPLP, apresentamos um panorama sobre tais instituições, como o sistema eleitoral, a duração do mandato dos parlamentares, o número de representantes, a quantidade de partidos com representação parlamentar e o número de comissões (Quadro 2).

\section{Mapeamento das informações disponíveis ao cidadão nos websites dos parlamentos}

A análise foi organizada em seis itens: informações gerais, estrutura e direção, atividades legislativas, prestação de contas sobre gastos, meios de divulgação institucional,

Quadro 1. Websites dos parlamentos dos países de língua portuguesa.

\begin{tabular}{|c|c|c|c|c|}
\hline & País & Instituição Legislativa & Tipo & Website \\
\hline 1 & Angola & $\begin{array}{l}\text { Assembleia Nacional de } \\
\text { Angola }\end{array}$ & Unicameral & http://www.parlamento.ao \\
\hline 2 & Brasil & Câmara dos Deputados & Bicameral & www.camara.leg.br \\
\hline 3 & Cabo Verde & $\begin{array}{l}\text { Assembleia Nacional de } \\
\text { Cabo Verde }\end{array}$ & Unicameral & http://www.parlamento.cv/ \\
\hline 4 & Guiné-Bissau & $\begin{array}{l}\text { Assembleia Nacional Popular } \\
\text { da República da Guiné-Bissau }\end{array}$ & Unicameral & http://www.anpguinebissau.org/assembleia \\
\hline 5 & Moçambique & $\begin{array}{l}\text { Assembleia da República de } \\
\text { Moçambique }\end{array}$ & Unicameral & www.parlamento.mz \\
\hline 6 & Portugal & Assembleia da República & Unicameral & http://www.parlamento.pt/ \\
\hline 7 & $\begin{array}{l}\text { S. Tomé e } \\
\text { Príncipe }\end{array}$ & $\begin{array}{l}\text { Assembleia Nacional de } \\
\text { São Tomé e Príncipe }\end{array}$ & Unicameral & www.parlamento.st \\
\hline 8 & Timor Leste & $\begin{array}{l}\text { Parlamento Nacional de } \\
\text { Timor-Leste }\end{array}$ & Unicameral & www.parlamento.tl \\
\hline
\end{tabular}

Fonte: Elaboração do autor.

Quadro 2. Perfil dos parlamentos da CPLP.

\begin{tabular}{|c|c|c|c|c|c|c|}
\hline & País & Eleição & Mandato & Representantes & $\begin{array}{l}\text { Partidos com } \\
\text { representantes }\end{array}$ & $\begin{array}{c}\text { Comissões } \\
\text { Permanentes }\end{array}$ \\
\hline 1 & Angola & $\begin{array}{l}\text { Proporcional, } \\
\text { lista fechada }\end{array}$ & 5 anos & 220 & 09 & 10 \\
\hline 2 & Brasil & $\begin{array}{l}\text { Proporcional, } \\
\text { lista aberta }\end{array}$ & 4 anos & 513 deputados & 32 & 22 \\
\hline 3 & Cabo Verde & $\begin{array}{l}\text { Proporcional, } \\
\text { lista aberta }\end{array}$ & 5 anos & 72 & 03 & 07 \\
\hline 4 & Guiné-Bissau & $\begin{array}{l}\text { Proporcional, } \\
\text { lista fechada }\end{array}$ & 5 anos & 102 & 18 & 08 \\
\hline 5 & Moçambique & $\begin{array}{l}\text { Proporcional, } \\
\text { lista fechada }\end{array}$ & 5 anos & 250 & 05 & 08 \\
\hline 6 & Portugal & $\begin{array}{l}\text { Proporcional, } \\
\text { lista fechada }\end{array}$ & 4 anos & 230 & 06 & 16 \\
\hline 7 & $\begin{array}{l}\text { S. Tomé e } \\
\text { Príncipe }\end{array}$ & $\begin{array}{l}\text { Proporcional, } \\
\text { lista fechada }\end{array}$ & 4 anos & 55 & 03 & 05 \\
\hline 8 & Timor Leste & $\begin{array}{l}\text { Proporcional, } \\
\text { lista fechada }\end{array}$ & 5 anos & 88 & 04 & 07 \\
\hline
\end{tabular}

Fonte: Elaboração do autor. 
contato e relacionamento com a sociedade. A escala utilizada toma o índice 1,00 como o valor máximo, para efeitos comparativos entre as oito instituições.

O Quadro 3 mostra o levantamento sobre as informações gerais disponíveis. A avaliação revela um bom desempenho de todos os parlamentos da CPLP nesse quesito, cujo índice de menor expressividade registrado é de 0,692, referente à Assembleia Nacional de Cabo Verde. Os índices mais elevados são da Câmara dos Deputados do Brasil e da Assembleia da República de Portugal, ambas com 1,00 de desempenho. Em segundo lugar está a Assembleia Nacional de Angola, com 0,923, seguida da Assembleia da República de Moçambique, com 0,846. Em quarto lugar estão empatadas com o mesmo índice: Assembleia Nacional Popular da República da GuinéBissau, Assembleia Nacional de São Tomé e Príncipe e Parlamento Nacional de Timor-Leste, todos com 0,769.

Quanto aos itens com desempenho superior estão as informações relativas às normas e funcionamento das instituições, a legislação de cada país, os relatórios de legislaturas anteriores, lista e biografia dos parlamentares, dados sobre parlamentos regionais e organismos interparlamentares. Os itens com desempenho inferior, por sua vez, são a divulgação das atas de votações do plenário e das comissões, as normas de decoro e de ética parlamentar, os relatórios anuais de atividades, e a biblioteca parlamentar.

No campo das informações gerais, o levantamento revela um nível elementar de transparência ativa, ou seja, aquela que compreende as informações divulgadas por iniciativa das próprias instituições. Trata-se de documentos de domínio público, em sua maioria, como a legislação do país, a biografia dos parlamentares, estatísticas sobre eleições e dados sobre as relações interparlamentares. Apesar disso, ainda existem déficites de transparência, mesmo em se tratando de informações básicas, como as atas das votações do plenário e das comissões. Nesse quesito, cinco dos oito parlamentos não publicam esses registros: $\mathrm{CV}, \mathrm{GB}, \mathrm{MZ}, \mathrm{ST}$, TL.

Em termos gerais, o tópico sobre as informações acerca da estrutura e a direção dos parlamentos também obteve um bom desempenho, com exceção da Assembleia Nacional Popular da República da Guiné-Bissau, que registra o menor índice, com 0,16 (Quadro 4). As demais ficaram na faixa de 0,58 a 1,00. No topo estão a Câmara dos Deputados do Brasil e o Parlamento Nacional de Timor-Leste. Em segundo lugar ficam a Assembleia Nacional de Cabo Verde e a Assembleia da República de Portugal, ambas com 0,83. Em terceiro lugar figura a Assembleia Nacional de São Tomé e Príncipe, com 0,66, seguida da Assembleia da República de Moçambique, com 0,58 .

Entre os itens de desempenho superior estão as informações sobre o presidente da instituição e os dados sobre os órgãos diretores dos parlamentos. No caso dos itens com menor desempenho predominam a falta de informações sobre os presidentes das comissões parlamentares e dados sobre os órgãos de correição e investigação parlamentar, como as corregedorias parlamentares e os conselhos de ética e decoro. São os órgãos responsáveis pela investigação de condutas inadequadas dos representantes. Apenas os parlamentos

Quadro 3. Informações gerais dos websites dos parlamentos da CPLP.

\begin{tabular}{|c|c|c|c|c|c|c|c|c|c|}
\hline & Dados & AO & BR & CV & GB & MZ & PT & ST & TL \\
\hline 1 & Regimento da Instituição & 1 & 1 & 1 & 1 & 1 & 1 & 1 & 1 \\
\hline 2 & Relatórios anuais de atividades & 1 & 1 & 0 & 0 & 1 & 1 & 1 & 1 \\
\hline 3 & $\begin{array}{l}\text { Biblioteca parlamentar, arquivos e serviços de } \\
\text { informação }\end{array}$ & 1 & 1 & 1 & 1 & 1 & 1 & 1 & 0 \\
\hline 4 & Atas de votações do Plenário & 1 & 1 & 0 & 0 & 0 & 1 & 0 & 0 \\
\hline 5 & Atas de votações das comissões & 1 & 1 & 0 & 0 & 0 & 1 & 0 & 0 \\
\hline 6 & Normas de funcionamento da instituição & 1 & 1 & 1 & 1 & 1 & 1 & 1 & 1 \\
\hline 7 & Código de Ética e Decoro Parlamentar & 0 & 1 & 0 & 1 & 1 & 1 & 0 & 1 \\
\hline 8 & Legislação do país & 1 & 1 & 1 & 1 & 1 & 1 & 1 & 1 \\
\hline 9 & Relatórios sobre legislaturas anteriores & 1 & 1 & 1 & 1 & 1 & 1 & 1 & 1 \\
\hline 10 & Lista e biografia dos parlamentares & 1 & 1 & 1 & 1 & 1 & 1 & 1 & 1 \\
\hline 11 & Dados sobre eleições parlamentares & 1 & 1 & 1 & 1 & 1 & 1 & 1 & 1 \\
\hline 12 & Informações sobre parlamentos regionais & 1 & 1 & 1 & 1 & 1 & 1 & 1 & 1 \\
\hline \multirow[t]{2}{*}{13} & Dados sobre organismos interparlamentares & 1 & 1 & 1 & 1 & 1 & 1 & 1 & 1 \\
\hline & Índice final & 0,923 & 1,00 & 0,692 & 0,769 & 0,846 & 1,0 & 0,769 & 0,769 \\
\hline
\end{tabular}

Fonte: Elaboração do autor. 
Quadro 4. Informações sobre a estrutura e a direção do parlamento.

\begin{tabular}{llcccccccc}
\hline \multicolumn{1}{c}{$\begin{array}{c}\text { Dados sobre a estrutura e a direção do } \\
\text { parlamento }\end{array}$} & AO & BR & CV & GB & MZ & PT & ST & TL \\
\hline 1 & Dados sobre o presidente da instituição & 1 & 1 & 1 & 1 & 1 & 1 & 1 & 1 \\
2 & Dados sobre a mesa-diretora & 1 & 1 & 1 & 1 & 1 & 1 & 1 & 1 \\
3 & Dados sobre as lideranças partidárias & 1 & 1 & 1 & 0 & 1 & 1 & 1 & 1 \\
4 & Dados sobre os presidentes das comissões & 1 & 1 & 1 & 0 & 1 & 1 & 1 & 1 \\
5 & Dados sobre os órgãos de correição e & 0 & 1 & 1 & 0 & 0 & 0 & 0 & 1 \\
& investigação parlamentar & & & & & & & & \\
6 & Dados sobre a direção dos demais órgãos & 1 & 1 & 0 & 0 & 0 & 1 & 1 & 1 \\
& legislativos & & & & & & & & \\
7 & Composição partidária do parlamento & 1 & 1 & 1 & 0 & 1 & 1 & 1 & 1 \\
8 & Blocos e coligações partidárias & 1 & 1 & 1 & 0 & 1 & 1 & 1 & 1 \\
9 & Composição das comissões parlamentares & 1 & 1 & 1 & 0 & 1 & 1 & 1 & 1 \\
10 & Perfil e foto do presidente & 0 & 1 & 1 & 0 & 0 & 1 & 0 & 1 \\
11 & Perfil e foto dos integrantes da Mesa Diretora & 0 & 1 & 1 & 0 & 0 & 1 & 0 & 1 \\
12 & Perfil e foto dos presidentes das comissões & 0 & 1 & 0 & 0 & 0 & 0 & 0 & 1 \\
& parlamentares & & & & & & & & \\
& Índice final & $\mathbf{0 , 6 6}$ & $\mathbf{1 , 0}$ & $\mathbf{0 , 8 3}$ & $\mathbf{0 , 1 6}$ & $\mathbf{0 , 5 8}$ & $\mathbf{0 , 8 3}$ & $\mathbf{0 , 6 6}$ & $\mathbf{1 , 0}$ \\
\hline
\end{tabular}

Fonte: Elaboração do autor.

de BR, CV e TL publicam informações sobre os processos de investigação contra parlamentares. Nos demais, esses dados são omitidos no websites. Caberia aprofundar se não há dados porque não existem representantes investigados ou se tal lacuna constitui omissão política.

Quanto às atividades legislativas, destacam-se a Câmara dos Deputados do Brasil e a Assembleia da República de Portugal, com 1,00 e 0,94, respectivamente. A Assembleia da República de Moçambique registra 0,61. Em seguida aparecem o Parlamento Nacional de Timor-Leste $(0,55)$ e a Assembleia Nacional de Angola $(0,50)$. Na sequência, estão Assembleia Nacional Popular da República da Guiné-Bissau e a Assembleia Nacional de São Tomé e Príncipe, ambas com 0,38. O índice menos expressivo fica para a Assembleia Nacional de Cabo Verde, com 0,27.

A performance de maior relevância diz respeito às informações sobre os projetos de leis em tramitação, a agenda do plenário e os tratados/acordos internacionais. Entre os tópicos mais deficitários de transparência estão a agenda de trabalho dos demais órgãos legislativos (excetuando-se o plenário e as comissões), o áudio e vídeo das sessões das comissões e do plenário.

Chama atenção a falta de informações ao público sobre a assiduidade dos parlamentares às sessões deliberativas. Apenas a Câmara dos Deputados brasileira publica em sua webpage relatórios mensais de presença dos deputados às sessões. $\mathrm{O}$ áudio e o vídeo das sessões das comissões são publicados apenas pela Câmara brasileira e a Assembleia portuguesa. Apenas três instituições publicam um glossário de termos legislativos: a Câmara brasileira, a Assembleia portuguesa e Assembleia de São Tomé e Princípe. É de notório reconhecimento que os procedimentos legislativos são complexos e exigem o domínio de um repertório técnico de difícil domínio pela maioria dos cidadãos. A publicação de glossário com termos legislativos poderia ajudar na compreensão do público interessado em acompanhar as atividades legislativas por meio da internet. Em alguns casos, faltam até informações elementares como as funções de cada órgão do parlamento, como se vê no Quadro 5.

Em relação à divulgação dos gastos e despesas das instituições parlamentares, há três níveis de transparência. A Câmara dos Deputados do Brasil representa o primeiro nível, com o índice mais elevado $(0,894)$. O segundo nível é composto por três parlamentos, com igual desempenho $(0,052)$ : Assembleia Nacional Popular da República da Guiné-Bissau, Assembleia da República de Moçambique e Assembleia Nacional de São Tomé e Príncipe. Por último, com ausência total de informações sobre as despesas estão a Assembleia Nacional de Angola, a Assembleia Nacional de Cabo Verde e o Parlamento Nacional de Timor-Leste. Excetuando-se a instituição brasileira, há uma carência expressiva de informações sobre as despesas dos parlamentos dos países da CPLP. Todos eles publicam apenas o orçamento geral do país, sem preocupação específica com os custos da 
Quadro 5. Informações sobre as atividades legislativas.

\begin{tabular}{llcccccccc}
\hline \multicolumn{1}{c}{ Informações sobre as atividades legislativas } & AO & BR & CV & GB & MZ & PT & ST & TL \\
\hline 1 & Informações sobre os projetos em tramitação & 1 & 1 & 1 & 1 & 1 & 1 & 1 & 1 \\
2 & Agenda do Plenário & 1 & 1 & 1 & 1 & 1 & 1 & 1 & 1 \\
3 & Agenda das comissões & 1 & 1 & 1 & 1 & 1 & 1 & 0 & 1 \\
4 & Agenda dos demais órgãos legislativos & 0 & 1 & 0 & 0 & 0 & 1 & 0 & 0 \\
5 & Discursos e pronunciamentos & 1 & 1 & 0 & 1 & 1 & 1 & 0 & 0 \\
6 & Atas das sessões & 1 & 1 & 0 & 1 & 1 & 1 & 0 & 1 \\
7 & Agenda do presidente & 0 & 1 & 0 & 1 & 1 & 1 & 1 & 1 \\
8 & Informações sobre o processo legislativo & 1 & 1 & 0 & 0 & 1 & 1 & 1 & 1 \\
9 & Informações sobre as funções de cada órgão do parlamento & 0 & 1 & 0 & 0 & 1 & 1 & 1 & 1 \\
10 & Relatórios de presença dos parlamentares às sessões & 0 & 1 & 0 & 0 & 0 & 0 & 0 & 0 \\
11 & Glossário de termos legislativos & 0 & 1 & 0 & 0 & 0 & 1 & 1 & 0 \\
12 & Áudio e vídeo das sessões do plenário & 1 & 1 & 0 & 0 & 0 & 1 & 0 & 0 \\
13 & Áudio e vídeo das sessões das comissões & 0 & 1 & 0 & 0 & 0 & 1 & 0 & 0 \\
14 & Dados sobre as bancadas temáticas & 1 & 1 & 0 & 0 & 1 & 1 & 0 & 1 \\
15 & Dados sobre as bancadas dos estados/províncias/regiões & 1 & 1 & 1 & 0 & 1 & 1 & 0 & 1 \\
16 & Tratados e acordos internacionais & 0 & 1 & 1 & 1 & 1 & 1 & 1 & 1 \\
& Índice final & $\mathbf{0 , 5 0}$ & $\mathbf{1 , 0}$ & $\mathbf{0 , 2 7}$ & $\mathbf{0 , 3 8}$ & $\mathbf{0 , 6 1}$ & $\mathbf{0 , 9 4}$ & $\mathbf{0 , 3 8}$ & $\mathbf{0 , 5 5}$ \\
\hline
\end{tabular}

Fonte: Elaboração do autor.

representação parlamentar, excetuando-se a Câmara dos Deputados brasileira, como se vê no Quadro 6.

Nesse tópico certamente a atuação da imprensa e de entidades não-governamentais em defesa da transparência política exercem influência direta na divulgação dos gastos e despesas das instituições políticas, como tem sido no caso do Brasil. Desde que foi criada no ano 2000, a Transparência Brasil (www.transparencia.org.br) passou a acompanhar sistematicamente os gastos do Poder Legislativo, fornecendo levantamentos completos para a imprensa. Esse modo de atuar favorece a visibilidade dessa agenda e aumenta a pressão social por maior transparência e accountability. Nos demais países, esse processo parece que tem produzido menos impacto, $\mathrm{o}$ que exigiria estudos contextuais para aprofundamento. $\mathrm{O}$ fato é que, conforme já foi argumentado, a transparência política é socialmente produzida, o que implica um interplay entre atores políticos e atores sociais. Quanto menor a transparência nas instituições parlamentares, certamente menor tem sido o engajamento dos demais atores e instituições sociais que exercem o papel de empreendores morais em defesa da qualidade da democracia (GUGLIANO, 2013).

No quesito divulgação institucional a Câmara dos Deputados do Brasil fica em primeiro lugar, com 1,00, seguida da Assembleia da República de Portugal, com 0,50 , como registrado no Quadro 7. Na sequência está a Assembleia da República de Moçambique, com
0,375. AAssembleia Nacional de Angola, a Assembleia Nacional de Cabo Verde e a Assembleia Nacional de São Tomé e Príncipe aparecem em seguida, com 0,312. Em último lugar estão a Assembleia Nacional Popular da República da Guiné-Bissau e o Parlamento Nacional de Timor-Leste, ambos com 0,250.

$\mathrm{O}$ uso da internet como mídia informativa, com a divulgação de noticiário eletrônico sobre o parlamento, é o principal recurso utilizado, seguido da possibilidade de download de conteúdos. Outro item contemplado por todas as instituições é a divulgação do diário oficial do parlamento, além de instrumentos de relacionamento com a mídia, com a divulgação de material informativo sobre o parlamento para a imprensa. A dimensão informativa prevalece, portanto. Apenas a Câmara dos Deputados do Brasil e a Assembleia da República de Portugal divulgam suas atividades por meio de canal próprio de televisão.

Os dados confirmam o uso da internet pelos parlamentos como um mural virtual (CASTELLS, 2003), com ênfase para o provimento de informações, seguindo a lógica da oferta de informações, ou seja, os websites das instituições atuam como emissores, com uma perspectiva próxima das chamadas mídias táticas (JURIS, 2005), que buscam enquadramentos informativos diferenciados e estratégicos, segundo a perspectiva dos próprios parlamentos. São também denominadas mídias 
Quadro 6. Prestação de contas sobre gastos e despesas dos parlamentos.

\begin{tabular}{|c|c|c|c|c|c|c|c|c|c|}
\hline & Prestação de contas & AO & BR & CV & GB & MZ & PT & ST & TL \\
\hline 2 & $\begin{array}{l}\text { Prestação de contas sobre os gastos } \\
\text { parlamentares }\end{array}$ & 0 & 1 & 0 & 1 & 0 & 0 & 0 & 0 \\
\hline 3 & Remuneração e subsídios dos parlamentares & 0 & 1 & 0 & 0 & 0 & 0 & 0 & 0 \\
\hline 4 & $\begin{array}{l}\text { Despesas com viagens oficiais, diárias e } \\
\text { passagens aéreas }\end{array}$ & 0 & 1 & 0 & 0 & 0 & 0 & 0 & 0 \\
\hline 5 & Informações sobre o valor da verba de gabinete & 0 & 1 & 0 & 0 & 0 & 0 & 0 & 0 \\
\hline 6 & Contratos e licitações & 0 & 1 & 0 & 1 & 1 & 0 & 1 & 0 \\
\hline 7 & $\begin{array}{l}\text { Gastos com planos de saúde para os } \\
\text { parlamentares }\end{array}$ & 0 & 1 & 0 & 0 & 0 & 0 & 0 & 0 \\
\hline 8 & $\begin{array}{l}\text { Gastos com aposentadoria e pensões dos } \\
\text { parlamentares }\end{array}$ & 0 & 1 & 0 & 0 & 0 & 0 & 0 & 0 \\
\hline 9 & $\begin{array}{l}\text { Gastos com transporte local e deslocamento dos } \\
\text { parlamentares }\end{array}$ & 0 & 1 & 0 & 0 & 0 & 0 & 0 & 0 \\
\hline 10 & Gastos com horas extras dos parlamentares & 0 & 1 & 0 & 0 & 0 & 0 & 0 & 0 \\
\hline 11 & Despesas com auxílio moradia dos parlamentares & 0 & 1 & 0 & 0 & 0 & 0 & 0 & 0 \\
\hline 12 & $\begin{array}{l}\text { Despesas com auxílio-alimentação dos } \\
\text { parlamentares }\end{array}$ & 0 & 0 & 0 & 0 & 0 & 0 & 0 & 0 \\
\hline 13 & $\begin{array}{l}\text { Prestação de contas sobre os escritórios } \\
\text { estaduais/provinciais/regionais }\end{array}$ & 0 & 0 & 0 & 0 & 0 & 0 & 0 & 0 \\
\hline 14 & $\begin{array}{l}\text { Dados sobre gastos com os gabinetes } \\
\text { parlamentares na sede }\end{array}$ & 0 & 1 & 0 & 0 & 0 & 0 & 0 & 0 \\
\hline \multirow[t]{2}{*}{15} & Relatórios de gestão financeira do parlamento & 0 & 1 & 0 & 0 & 0 & 0 & 0 & 0 \\
\hline & Índice final & $\mathbf{0}$ & 0,894 & $\mathbf{0}$ & 0,052 & 0,052 & $\mathbf{0}$ & 0,052 & $\mathbf{0}$ \\
\hline
\end{tabular}

Fonte: Elaboração do autor.

Quadro 7. Meios de divulgação institucional.

\begin{tabular}{llcccccccc}
\hline \multicolumn{1}{c}{ Meios de divulgação institucional } & AO & BR & CV & GB & MZ & PT & ST & TL \\
\hline 1 & Noticiário eletrônico online & 1 & 1 & 1 & 1 & 1 & 1 & 1 & 1 \\
2 & Canal de televisão legislativa & 0 & 1 & 0 & 0 & 0 & 1 & 0 & 0 \\
3 & Webtv & 0 & 1 & 0 & 0 & 0 & 1 & 0 & 0 \\
4 & Emissora de rádio & 0 & 1 & 0 & 0 & 0 & 0 & 0 & 0 \\
5 & Webrádio & 0 & 1 & 0 & 0 & 0 & 0 & 0 & 0 \\
6 & Download de conteúdos & 1 & 1 & 1 & 1 & 1 & 1 & 1 & 1 \\
8 & Clipping de notícias sobre o parlamento & 0 & 1 & 0 & 0 & 0 & 0 & 0 & 0 \\
9 & Blogs dos órgãos parlamentares & 0 & 1 & 0 & 0 & 0 & 1 & 0 & 0 \\
10 & Diário oficial do parlamento & 1 & 1 & 1 & 1 & 1 & 1 & 1 & 1 \\
11 & Material de divulgação para a imprensa & 1 & 1 & 1 & 1 & 1 & 1 & 1 & 1 \\
11 & Banco de imagens dos eventos legislativos & 1 & 1 & 0 & 0 & 1 & 0 & 0 & 0 \\
13 & Entrevistas com parlamentares & 0 & 1 & 0 & 0 & 1 & 0 & 0 & 0 \\
14 & Debates com parlamentares & 0 & 1 & 1 & 0 & 0 & 1 & 1 & 0 \\
15 & Índice final & $\mathbf{0 , 3 1 2}$ & $\mathbf{1 , 0}$ & $\mathbf{0 , 3 1 2}$ & $\mathbf{0 , 2 5 0}$ & $\mathbf{0 , 3 7 5}$ & $\mathbf{0 , 5 0}$ & $\mathbf{0 , 3 1 2}$ & $\mathbf{0 , 2 5 0}$ \\
\hline
\end{tabular}

Fonte: Elaboração do autor. 
das fontes (SANT'ANNA, 2008), ou seja, mantidas e administradas pelas próprias instituições.

Em suma, percebe-se um baixo investimento em modalidades diversificadas de divulgação institucional que se aproximem da lógica da demanda ou das mídias segmentadas (WOLTON, 2006). Apesar das possibilidades e do baixo custo da internet, recursos como blogs, webtv e webrádio, por exemplo, ainda não são explorados pela maioria dos parlamentos dos países da CPLP. A Câmara dos Deputados brasileira figura como exceção, o que se justifica pelo seu projeto institucional de divulgação em mídias das fontes e seu projeto de parlamento aberto (FARIA, 2012).

Quanto às interfaces institucionais com a sociedade e formas de mediação com setores da esfera civil, mais uma vez, a Câmara dos Deputados do Brasil apresenta o maior desempenho, com 0,969. A Assembleia da República de Portugal aparece em segundo lugar, com 0,393 . O terceiro lugar fica para a Assembleia Nacional Popular da República da Guiné-Bissau, com 0,272. Em quarto lugar empatam com 0,242 a Assembleia da República de Moçambique e a Assembleia Nacional de São Tomé e Príncipe. Os menores índices são registrados, respectivamente pelo Parlamento Nacional de Timor-Leste $(0,212)$, Assembleia Nacional de Angola e Assembleia Nacional de Cabo Verde (ambos com 0,151).
Os itens de melhor desempenho dizem respeito à divulgação de informações básicas, como endereço, número telefônico e correio eletrônico das instituições, além de ferramenta de busca para consultas temáticas nos websites. Nos demais quesitos avaliados observa-se um elevado déficite de estratégias de contato e relacionamento com a sociedade, apesar das alternativas oferecidas pelos mecanismos digitais de interação. Mesmo instrumentos simples como tour cívico virtual aparecem apenas nos websites da Câmara dos Deputados do Brasil, da Assembleia da República de Portugal e da Assembleia Nacional de São Tomé e Príncipe.

O levantamento mostra baixa adesão dos parlamentos dos países da CPLP aos recursos da democracia digital e de parlamento aberto (FARIA, 2012). Alguns dados chamam atenção, como a inexistência de serviço telefônico para atendimento ao cidadão, exceto a instituição brasileira. Apesar dos avanços e da expansão da internet, é sabido que ainda existem dificuldades para muitos cidadãos desses países, especialmente no caso das nações africanas, para uso cotidiano de internet com banda larga. Assim, um sistema telefônico de atendimento constitui uma alternativa. No campo digital, as lacunas identificadas, conforme o Quadro 8, são as seguintes: falta de ferramenta para comentários do público sobre os projetos de leis em tramitação, inexistência de mecanismos que permitam interatividade efetiva com

Quadro 8. Meios de contato e relacionamento com a sociedade.

\begin{tabular}{|c|c|c|c|c|c|c|c|c|c|}
\hline & Contato e relacionamento com a sociedade & AO & BR & $\mathbf{C V}$ & GB & MZ & PT & ST & TL \\
\hline 1 & $\begin{array}{l}\text { Formas de contato com a Presidência do } \\
\text { parlamento }\end{array}$ & 0 & 1 & 1 & 1 & 1 & 1 & 1 & 1 \\
\hline 2 & $\begin{array}{l}\text { Formas de contato com os demais órgãos da } \\
\text { direção }\end{array}$ & 0 & 1 & 0 & 1 & 1 & 1 & 1 & 1 \\
\hline 3 & Formas de contato com as comissões & 0 & 1 & 0 & 1 & 1 & 1 & 1 & 1 \\
\hline 5 & Endereço da instituição & 1 & 1 & 1 & 1 & 1 & 1 & 1 & 1 \\
\hline 6 & N. de telefone e e-mail da instituição & 1 & 1 & 1 & 1 & 1 & 1 & 1 & 1 \\
\hline 7 & Serviço telefônico de atendimento ao cidadão & 0 & 1 & 0 & 0 & 0 & 0 & 0 & 0 \\
\hline 8 & Serviço digital de atendimento ao cidadão & 1 & 1 & 1 & 1 & 1 & 1 & 1 & 1 \\
\hline 9 & Comentários sobre os projetos/proposições & 0 & 1 & 0 & 0 & 0 & 0 & 0 & 0 \\
\hline 10 & Chats com parlamentares & 0 & 1 & 0 & 0 & 0 & 0 & 0 & 0 \\
\hline 11 & Ferramentas de busca para consultas temáticas & 1 & 1 & 1 & 1 & 1 & 1 & 1 & 1 \\
\hline 12 & Tira-dúvidas sobre temas legislativos & 0 & 1 & 0 & 0 & 0 & 1 & 0 & 0 \\
\hline 13 & E-Petições legislativas & 1 & 0 & 0 & 0 & 0 & 1 & 0 & 0 \\
\hline 14 & Fóruns sobre temas legislativos & 0 & 1 & 0 & 0 & 0 & 0 & 0 & 0 \\
\hline 15 & Links para redes sociais & 0 & 1 & 0 & 0 & 0 & 0 & 0 & 0 \\
\hline 16 & Comentários em notícias & 0 & 1 & 0 & 0 & 1 & 0 & 0 & 0 \\
\hline 17 & Newsletter & 0 & 1 & 0 & 0 & 0 & 1 & 0 & 0 \\
\hline 18 & Enquetes sobre temas políticos & 0 & 1 & 0 & 1 & 0 & 0 & 0 & 0 \\
\hline 19 & Resultados das enquetes & 0 & 1 & 0 & 1 & 0 & 0 & 0 & 0 \\
\hline 20 & Programas de educação política & 0 & 1 & 0 & 0 & 0 & 1 & 0 & 0 \\
\hline 21 & Visitação cívica guiada & 0 & 1 & 0 & 0 & 0 & 1 & 0 & 0 \\
\hline \multirow[t]{2}{*}{22} & Tour cívico virtual & 0 & 1 & 0 & 0 & 0 & 1 & 1 & 0 \\
\hline & Índice final & $\mathbf{0 , 1 5 1}$ & 0,969 & 0,151 & $\mathbf{0 , 2 7 2}$ & 0,242 & 0,393 & 0,242 & 0,212 \\
\hline
\end{tabular}

Fonte: Elaboração do autor. 
Quadro 9. Índice geral.

\begin{tabular}{llcccccccc}
\hline \multicolumn{1}{c}{ Itens } & BR & PT & TL & MZ & AO & ST & CV & GB \\
\hline 1 & Informações gerais & 1,00 & 1,00 & 0,769 & 0,846 & 0,923 & 0,769 & 0,692 & 0,769 \\
2 & Estrutura e direção & 1,00 & 0,830 & 1,00 & 0,580 & 0,666 & 0,666 & 0,830 & 0,160 \\
3 & Atividades legislativas & 1,00 & 0,940 & 0,555 & 0,610 & 0,500 & 0,380 & 0,270 & 0,380 \\
4 & Prestação de contas & 0,894 & 0,000 & 0,000 & 0,052 & 0,000 & 0,052 & 0,000 & 0,052 \\
5 & Divulgação institucional & 1,00 & 0,500 & 0,250 & 0,375 & 0,312 & 0,312 & 0,312 & 0,250 \\
6 & Contato e relacionamento & 0,969 & 0,393 & 0,212 & 0,242 & 0,151 & 0,242 & 0,151 & 0,272 \\
& Total & 5,863 & 3,663 & 2,786 & 2,705 & 2,552 & 2,421 & 2,255 & 1,883 \\
& Índice final & $\mathbf{0 , 9 7 7}$ & $\mathbf{0 , 6 1 0}$ & $\mathbf{0 , 4 6 4}$ & $\mathbf{0 , 4 5 0}$ & $\mathbf{0 , 4 2 5}$ & $\mathbf{0 , 4 0 3}$ & $\mathbf{0 , 3 7 5}$ & $\mathbf{0 , 3 1 3}$ \\
& Classificação final & 1 & 2 & 3 & 4 & 5 & 6 & 7 & 8 \\
\hline
\end{tabular}

os parlamentares, além da impossibilidade de assinatura de e-petições, de newsletter sobre temas legislativos, de enquetes e de programas de educação política.

Considerando o índice geral de desempenho, a partir do somatório dos seis itens avaliados, o Quadro 9 mostra a classificação final, com a Câmara dos Deputados do Brasil em primeiro lugar e a Assembleia da República de Portugal em segundo, com 0,977 e 0,610, respectivamente. Em terceiro lugar aparece o Parlamento Nacional de Timor-Leste, com 0,464, seguido da Assembleia da República de Moçambique, com 0,450. Na sequência temos: a Assembleia Nacional de Angola $(0,425)$, a Assembleia Nacional de São Tomé e Príncipe $(0,403)$, a Assembleia Nacional de Cabo Verde $(0,375)$ e a Assembleia Nacional Popular da República da GuinéBissau $(0,313)$.

\section{Considerações finais}

Os dados mostram que a internet já é de uso generalizado nos parlamentos dos países de língua portuguesa, como ocorre nas demais instituições de representação parlamentar (FRICK, 2004; TRECHSEL et al., 2004; LESTON-BANDEIRA, 2012). Ressalvadas as iniciativas mais abrangentes da Câmara dos Deputados do Brasil e da Assembleia da República de Portugal, conclui-se que ainda faltam estratégias mais efetivas de transparência pelas demais instituições da CPLP. Os potenciais democráticos da internet e suas ferramentas de transparência digital, apontados na primeira parte do texto por autores como Silva et al. (2009) ainda estão distantes de serem plenamente concretizados pela maioria das casas legislativas dos países da CPLP.

A baixa disposição da maioria das instituições em estudo, conforme mostram os dados, para o investimento em accountability digital pode comprometer a legitimidade e a confiança dos cidadãos. Além disso, reduz as chances de aumentar a satisfação da população com o desenvolvimento dos regimes democráticos (NORRIS, 1999; LIJPHART, 2001; TILLY, 2008). As conclusões indicam que nos parlamentos de países como Angola, Cabo verde, Guiné-Bissau, Moçambique, São Tomé e Príncipe, e Timor Leste ainda estão distantes da concepção de parlamento aberto (FARIA, 2012), uma vez que a internet tem sido subutilizada do ponto de vista de conexão das instituições parlamentares com a sociedade. A transparência é apontada na literatura especializada como um dos requisitos inerentes às instituições parlamentares, além da probidade, da representatividade, acessibilidade, responsabilidade e eficácia política (SÁEZ; MERCEDEZ, 2013). Nesse quesito, as instituições mencionadas ainda são nitidamente deficitárias, como mostram os dados.

Chama atenção ainda a primazia da função informativa dos websites dos parlamentos da CPLP, em detrimento das funções de interação, participação cidadã e debate sobre os temas em discussão nas instituições parlamentares. Esse diagnóstico confirma uma série de estudos empíricos já realizados sobre as lógicas de usabilidade das mídias digitais por instituições políticas (BRAGA; BLANCHARD; MARQUES, 2005; RÖMMELE, 2003). Acreditamos, contudo, que mais do que corroborar trilhas analíticas, é mais importante também uma reflexão sobre o que isso significa, em termos de compreensão da política informacional das instituições legislativas.

Nessa perspectiva, Marques (2005, p. 143) avalia que o potencial da internet no campo político, até o momento, limita-se à exploração da "grande facilidade para se alcançar determinado público e distribuir materiais", com o propósito de reforçar visões e representações políticas "e não para tornar os cidadãos mais próximos da discussão e do aperfeiçoamento das políticas e projetos para o país".

Sob o ângulo dos estudos sociomediáticos, a análise revela que as instituições parlamentares da CPLP ainda utilizam as "novas mídias", com a mesma lógica das 
"velhas mídias". O mesmo autor supracitado ressalva que, apesar das possibilidades de democracia digital, em termos de ferramentas interativas e dialógicas oferecidas pelas internet, permanece uma lógica unidirecional de oferta de conteúdos. Depreende-se, pois, que não se trata de carência de meios técnicos, mas de disposição de instituições e atores-chaves no processo de formulação e decisão da coisa pública (MARQUES, 2005, p. 144). Essa dissonância em relação aos prognósticos democratizantes e ao "imaginário da cibercultura" (LEMOS, 1998) conduz a vários questionamentos sobre o alcance efetivo da internet em termos de promoção de maior interação entre a esfera da representação e a esfera civil, o que lembra a observação de Pipa Norris (2003) de que o uso político das mídias digitais apenas reforça o uso dos demais meios de informação, uma vez que os cidadãos que buscam esses canais para fins políticos são aqueles que já mostravam algum engajamento fora da esfera virtual. Em outras palavras, seria "pregar para os convertidos".

Em termos políticos, as implicações decorrentes desse diagnóstico revelado pelas conclusões do estudo é que a accountability é a principal função dos websites dos parlamentos dos países da CPLP, em consonância com os argumentos de Karlsson (2013), porém com pouca relevância para as demais funções políticas das mídias digitais, como inquiry e connectivity, o que reafirma o caráter unidirecional já apontado, desprovido de porosidade social. As duas últimas funções apontadas dizem respeito a um conjunto de estratégias para captar as percepções dos cidadãos, auscultar a opinião dos usuários dos websites e oferecer possibilidades de interação e participação nos debates que se desenrolam no interior das arenas legislativas. Ao privilegiar somente a primeira função, os parlamentos da CPLP usam a visibilidade no âmbito virtual como recurso simbólico para a renovação da sua legitimidade perante os usuários de internet que acessam suas webpages.

Dessa forma, as instituições parlamentares delimitam simbolicamente os papeis políticos e reforçam a visão liberal da divisão do trabalho político entre os representantes como agentes peritos do campo político e os cidadãos como leigos, meros receptores das informações e espectadores do teatro político. A função de debate, por exemplo, mantém-se como exclusiva dos parlamentares, os responsáveis pela formulação das políticas públicas e pela definição dos enquadramentos interpretativos referentes aos projetos de lei em tramitação. O cidadão é mantido à distância do processo político, portanto, principalmente no que diz respeito à esfera decisória, reforçando o papel do parlamento como agência deliberativa.
Por fim, é oportuno ressaltar os índices de baixo acesso da população na maioria dos países da CPLP, especialmente no caso de Angola, Guiné-Bissau São Tomé e Príncipe, Timor Leste. São nações que ainda se encontram em situação de divisão digital (CASTELLS, 2003, p. 221), ou seja, um tipo de divisão entre os países que detêm os recursos econômicos, políticos e culturais para operar na esfera digital e os que ficam excluídos do mundo das interconexões. A situação mais favorável é a de Portugal, onde a média de acesso da população é de $80 \%$. No Brasil, o acesso à internet ainda é limitado à metade da população. A exclusão digital faz com que os parlamentos da maioria dos países da CPLP prestem contas de suas atividades apenas a restritas parcelas da população, excluindo grandes segmentos, mesmo do ponto de vista informativo. Essas informações circulam em núcleos privilegiados das sociedades, atingindo quase sempre as elites e setores com maior poder aquisitivo e capital cultural. Levantamentos recentes mostram que nos países da CPLP situados na África, as médias de acesso ainda estão na faixa de 15 a $35 \%$, segundo dados da Universidade da Integração Internacional da Lusofonia Afro-Brasileira UNILAB, de 2014.

\section{Referências}

ANASTASIA, F.; MELO, C. R.; SANTOS, F. Governabilidade e representação política na América do Sul. São Paulo: Editora UNESP, 2004.

BAUMAN, Z. Em busca da política. Rio de Janeiro: Zahar, 2000.

BECK, U.; GIDDENS, A.; LASH, S. Modernização Reflexiva. São Paulo: EdUnesp, 1994.

BLANCHARD, G. O uso da internet a serviço da comunicação do partido. Revista Líbero, v. 9, n. 18, 2008.

BOBBIO, N. Estado, governo, sociedade. Para uma teoria geral da politica. 12. ed. Rio de Janeiro: Paz e Terra, 2005.

BRAGA, S. S. Podem as novas tecnologias de informação e comunicação auxiliar na consolidação das democracias? Um estudo sobre a informatização dos órgãos legislativos na América do Sul. Opinião Pública, v. 13, n. 1, p. 1-50, 2007.

CASTELLS, M. A galáxia da internet. Rio de Janeiro: Zahar, 2003.

FARIA, C. F. O parlamento aberto na era da internet: pode o povo colaborar com o Legislativo na elaboração das leis? Brasília: Câmara dos Deputados, Edições Câmara, 2012.

FIGUEIREDO, V. Produção social da tecnologia. São Paulo: EPU, 1989.

FRIC, M. M. Parlamentos en la era digital: explorando América Latina. Teorías, Prácticas y Estrategias de Cambio, v. 18, n. 9, p. 123-159, 2004. 
GIDDENS, A. As consequências da modernidade. São Paulo: Editora Unesp, 1991.

GIDDENS, A. As consequências da modernidade. São Paulo: Editora da Unesp, 1990.

GIDDENS, A. A constituição da sociedade. São Paulo: Martins Fontes, 2009.

GUGLIANO, A. A. Apontamentos sobre o conceito de qualidade da democracia. Debates, Porto Alegre, v. 7, n. 1, p. 299-243, 2013.

HARVEY, D. Condição pós-moderna. São Paulo: Loyola, 1992.

JURIS, J. S. The new media and activist networking within anticorporate globalization movements. The Annals of the American Academy of Political and Social Science, v. 597, n. 1, p. 189-208, 2005. http:// dx.doi.org/10.1177/0002716204270338.

KARLSSON, M. Representation as interactive communication. Information Communication and Society, v. 16, n. 8, p. 1201-1220, 2013. http://dx.doi.org/10.1080/1369 118X.2012.757633.

LEMOS, A. O imaginario da cibercultura. Sao Paulo em Perspectiva, v. 12, n. 4, p. 46-53, 1998.

LESTON-BANDEIRA, C. Studying the relationship between parliament and citizens. Journal of Legislative Studies, v. 18, n. 3-4, p. 265-274, 2012. http://dx.doi. org/10.1080/13572334.2012.706044.

LIJPHART, A. Democracy in the 21 st century: can web e optimistic? European Review (Chichester, England), v. 9, n. 2, p. 169-184, 2001. http://dx.doi.org/10.1017/ S1062798701000163.

MANIN, B. As metamorfoses do governo representativo. Revista Brasileira de Ciências Sociais, v. 10, n. 29, p. 5-34, 1995.

MANIN, B. A democracia do público reconsiderada. Novos Estudos-CEBRAP, n. 97, p. 115-127, 2013.

MARQUES, F. P. J.A. Sobre a comunicação político-partidária na Internet: um estudo dos informativos digitais do PT e do PSDB. Revista Galáxia, n. 10, p. 129-146, 2005.

MIGUEL, L. F. A mídia e o declínio da confiança na política. Sociologias, Porto Alegre, v. 10, n. 19, p. 250-273, 2008. http://dx.doi.org/10.1590/S151745222008000100011.

MOISÉS, J.A. Democracia e desconfiança de instituições democráticas. São Paulo: EDUSP, 2009.
NORRIS, P. Critical citizens: global support for democratic government: global support for democratic government. Oxford: Oxford University Press, 1999.

NORRIS, P. Preaching to the converted? Pluralism, participation and party websites. Party Politics, v. 9, n. 1, p. 21-45, 2003. http://dx.doi.org/10.1177/135406880391003.

RIBEIRO, E. A. Confiança política na América Latina: evolução recente e determinantes individuais. Revista de Sociologia e Política, v. 19, n. 39, p. 167-182, 2011.

RIBEIRO, G. L. Cultura e política no mundo contemporâneo. Brasília, EdUnB, 2000.

RÖMMELE, A. Political parties, party communication and new information and communication technologies. Party Politics, v. 9, n. 1, p. 7-20, 2003.

SÁEZ, M.A.; MERCEDEZ, M. G. ?Parlamientos abiertos? Análisis comparado de la probidade y transparencia parlamentaria em América Latina. Buenos Aires: Banco Interamericano de Desenvolvimento, 2013.

SANT'ANNA, F. Midia das fontes. Brasília: Casa das Musas, 2008.

SILVA, S. P. et al. Publicidade, accountability e participação nos parlamentos online da América Latina. In: SEMINÁRIO NACIONAL DE SOCIOLOGIA E POLÍTICA, 1., 2009, Curitiba. Anais... Curitiba: Universidade Federal do Paraná, 2009.

THOMPSON, J. B. Ideologia e cultura moderna. Petrópolis: Vozes, 1995.

TILLY, C. Democracy. New York: Cambridge University Press, 2008.

TRECHSEL, A., et al. Evaluation of the use of new technologies in order to facilitate democracy in Europe: e-democratizating the parliaments and parties in Europe. Genebra: European University Institute, 2004.

URBINATI, N. O que torna a representação democrática. Lua Nova: Revista de Cultura e Política, n. 67, p. 191-228, 2006. Disponível em: <http://www.scielo. br/pdf/ln/n67/a07n67.pdf>. Acesso em: 01 jun. 2013.

WEBER, M. Economia e sociedade. Brasília: Editora da UnB, 1999.

WOLTON, D. Internet, e depois? Uma teoria crítica das novas mídias. São Paulo: Paulus, 2006.

Recebido: 10 abr., 2015 Aceito: 25 jul., 2015 